\title{
Reducing the Number of People with Dementia Through Primary Prevention in Mozambique, Brazil, and Portugal: An Analysis of Population-Based Data
}

\author{
Deborah Oliveira $^{\mathrm{a}}$, Leonardo Jun Otuyama ${ }^{\mathrm{a}, \mathrm{b}}$, Dirceu Mabunda $^{\mathrm{c}}$, Flavio Mandlate ${ }^{\mathrm{c}}$, \\ Manuel Gonçalves-Pereira ${ }^{\mathrm{d}}$, Miguel Xavier ${ }^{\mathrm{d}}$, Jerson Laks ${ }^{\mathrm{e}}$ and Cleusa P. Ferri ${ }^{\mathrm{a}, \mathrm{f}, *}$ \\ ${ }^{a}$ Universidade Federal de Sao Paulo, Departments of Psychobiology and Department of Psychiatry Sao Paulo, \\ Brazil \\ ${ }^{\mathrm{b}}$ Universidade de Sao Paulo - Hospital das Clinicas da Faculdade de Medicina, Sao Paulo, Brazil \\ ${ }^{\mathrm{c}}$ Eduardo Mondlane University, Faculty of Medicine, Maputo, Mozambique \\ ${ }^{\mathrm{d}}$ Universidade Nova de Lisboa, Nova Medical School/Faculdade de Ciências Médicas, Lisboa, Portugal \\ ${ }^{\mathrm{e}}$ Universidade Federal do Rio de Janeiro, Brazil; Universidade do Grande Rio, Duque de Caxias, \\ Rio de Janeiro, Brazil \\ ${ }^{\mathrm{f}}$ Hospital Alemao Osvaldo Cruz - Health Technology Assessment Unit, Sao Paulo, Brazil
}

Accepted 21 November 2018

\begin{abstract}
.
Background: Most people with dementia live in low- and middle-income countries and little is known about the potential for reducing these numbers by reducing key risk factors.

Objective: To investigate the potential for dementia incidence reduction in Brazil, Mozambique, and Portugal (a culturally related, high-income country).

Methods: We replicated previously published methods and based on the relative risks from previous studies, we estimated the population-attributable risk (PAR) of dementia in Mozambique, Brazil, and Portugal for seven modifiable risk factors associated with dementia (low educational attainment, physical inactivity, midlife hypertension, midlife obesity, depression, smoking, and diabetes mellitus). The combined PAR was calculated and adjusted for associations between risk factors. The potential for risk factor reduction was assessed by examining the effect of relative reductions of $10 \%$ and $20 \%$ per decade for each of the risk factors on projections for dementia cases for each decade until 2050.

Results: After adjusting for non-independence of risk factors, $24.4 \%, 32.3 \%$, and $40.1 \%$ of dementia cases could be related to seven potentially modifiable risk factors in Mozambique, Brazil, and Portugal, respectively. Reducing the prevalence of each risk factor by $20 \%$ per decade could, by 2050 , potentially reduce the prevalence of dementia in Mozambique, Brazil, and Portugal by $12.9 \%, 16.2 \%$, and $19.5 \%$, respectively.
\end{abstract}

${ }^{*}$ Correspondence to: Cleusa P. Ferri, Rua Napoleão de Barros, 925, 1st floor-04024-002, Vila Clementino, Sao Paulo, SP, Brazil. E-mail: ferricleusa@gmail.com. 
Conclusion: There is a substantial difference between the countries in the percentage of dementia cases that could be attributable to the seven potentially modifiable risk factors. The proportion of cases that could be prevented by 2050 if measures were taken to address these main risk factors was higher in Portugal than in Brazil and Mozambique. Each country or region should consider their unique risk factor profile when developing dementia risk reduction programs.

Keywords: Alzheimer's disease, dementia, low- and middle-income countries, prevention, risk reduction

\section{INTRODUCTION}

The number of people living with dementia is increasing rapidly worldwide. It has been estimated that around 50 million people had dementia in 2017, and this number is expected to reach 131.5 million in 2050 [1]. About $58 \%$ of these individuals are living in low- and middle-income countries (LMICs) and this is expected to rise to $68 \%$ by 2050 . Attempts to stop its progression or cure dementia have so far failed, meaning that delaying the disease onset is currently the only way to reduce the number of people affected by this set of conditions in the near future [2].

Around a third of dementia cases may be attributable to potentially modifiable risk factors and the incidence of the disease might be reduced by targeting these. The most important are cardiovascular related risk factors (e.g., physical inactivity, smoking, midlife hypertension, midlife obesity, and diabetes), education level, and depression [2,3]. Delaying the onset of dementia by one year is likely to reduce the prevalence of dementia by $11 \%$ by 2050 . If the incidence could be delayed by five years, the total number of people living with dementia could be halved by 2050 [4]. However, the common risk factors for dementia have been established based on data from high-income countries [2], and it is unclear which factors will have an effect on dementia prevalence in LMICs. These countries have different demographic and epidemiological profiles, which might have important implications for the effectiveness of preventive actions.

Brazil, Mozambique, and Portugal are three Lusophone countries that have markedly different demographic, epidemiological, and economic conditions. Brazil is a middle-income country with a life expectancy of almost 75 years of age and with an older population (over 65) of around 12\% [5]. Life expectancy in Brazil will reach 82 years of age by 2050 , when $29 \%$ of the population will be aged over 65. Mozambique, on the other hand, is a low-income country with a life expectancy of 56 years of age and an older population (over 65) of around 5\% [6]. Their life expectancy is expected to increase to 69 by
2050, when the proportion of older people will reach $6 \%$. Portugal is a high-income country that has a life expectancy of 82 years of age and $27 \%$ are aged over 65 . By 2050 , these figures are expected to increase to 87 and $41 \%$, respectively [7].

Understanding the relationship between the prevalence of risk factors and dementia prevalence in LMICs countries is important to inform public policy and take cost-effective steps to help reduce the high prevalence of this condition in the future and the consequent financial burden imposed on such countries. The prevalence of several communicable diseases, such as malaria and HIV, is still high in many LMICs and so their public health priorities may be quite different to those of the high-income countries. It is important to know the probable impact of measures to address dementia risk factors in order to develop the most effective policies and strategies for each context. This study therefore aimed to investigate the potential for dementia incidence reduction in Brazil, Mozambique, and Portugal by using existing data to estimate the population-attributable risk (PAR) of dementia for seven potentially modifiable risk factors in each of these countries.

\section{METHODS}

We replicated the methodology of Barnes and Yaffe [8] and Norton et al. [2] for our estimates and the same seven main risk factors, which were based on a systematic review and meta-analyses of the most prevalent modifiable risk factors for Alzheimer's disease. Although the study considered only the modifiable risk factors for Alzheimer's disease while we in our study consider the prevalence of dementia in general, it is generally accepted that the seven risk factors can be applied to the most common forms of dementia in the older populations as they are mixed in nature [3]. We selected Mozambique, Brazil, and Portugal for our estimates, to reflect low, middle, and high-income countries that are culturally related. The prevalence of each of the seven risk factors in Brazil, Mozambique, and Portugal were taken from various population-derived sources, including the National 
Table 1

Communality of dementia risk factors, their definition and relative risk for dementia

\begin{tabular}{|c|c|c|c|}
\hline Risk Factor & Definition used & $\begin{array}{c}\text { Relative risk } \\
(95 \% \mathrm{CI})\end{array}$ & Communality \\
\hline Diabetes mellitus & $\begin{array}{l}\text { Adult prevalence of diagnosed diabetes } \\
\text { mellitus between the ages of } 20 \text { years } \\
\text { and } 79 \text { years }\end{array}$ & $1.46(1.20-1.77)$ & $50.9 \%$ \\
\hline $\begin{array}{l}\text { Midlife } \\
\text { hypertension }\end{array}$ & $\begin{array}{l}\text { Adult midlife prevalence of hypertension } \\
\text { between the ages of } 35 \text { years and } \\
64 \text { years }\end{array}$ & $1.61(1.16-2.24)$ & $65.0 \%$ \\
\hline Midlife obesity & $\begin{array}{l}\text { Adult midlife prevalence of body-mass } \\
\text { index greater than } 30 \mathrm{~kg} / \mathrm{m}^{2} \text { between } \\
\text { the ages of } 35 \text { years and } 64 \text { years }\end{array}$ & $1.60(1.34-1.92)$ & $43.7 \%$ \\
\hline Physical inactivity & $\begin{array}{l}\text { Proportion of adults who do not do either } \\
20 \text { min of vigorous activity on } 3 \text { or } \\
\text { more days or } 30 \text { min of moderate } \\
\text { activity on } 5 \text { or more days per week }\end{array}$ & $1.82(1.19-2.78)$ & $49.0 \%$ \\
\hline Depression & $\begin{array}{l}\text { Lifetime prevalence of major depressive } \\
\text { disorder using Diagnostic and } \\
\text { Statistical Manual of Mental Disorders } \\
\text { or International Classification of } \\
\text { Diseases criteria }\end{array}$ & $1.65(1.42-1.92)$ & $37.4 \%$ \\
\hline Smoking & The proportion of adult smokers & $1.59(1.15-2.20)$ & $58.1 \%$ \\
\hline $\begin{array}{l}\text { Low educational } \\
\text { attainment }\end{array}$ & $\begin{array}{l}\text { The proportion of adults with an } \\
\text { International Standard Classification } \\
\text { of Education } 15 \text { level of } 2 \text { or less } \\
\text { (pre-primary, primary, and lower } \\
\text { secondary education) }\end{array}$ & $1.59(1.35-1.86)$ & $45.6 \%$ \\
\hline
\end{tabular}

Based on Norton et al. [2].

Sample Household Survey (PNAD) and the National Health Survey (PNAS) in Brazil [5], as well as published epidemiological studies from Mozambique [9-14] and Portugal [7, 15-19]. Table 1 lists the investigated risk factors, their relative risks and shared variance.

\section{Statistical analysis}

To estimate the proportion of cases of dementia that can be attributable to each risk factor, we calculated the PAR based on previous publications $[8,19]$. Using the same methods as Barnes and Yaffe [8] and Norton et al. [2], the PAR for each of the risk factors was calculated using the formula presented in (a), and then combined to obtain the $\mathrm{PAR}_{\text {combined, }}$ using the formula in (b), which shows the proportion of cases of dementia attributable to the seven risk factors. However, the PAR combined formula assumes the independence of each risk factor. This is not representative for people with dementia, since one individual may present with more than one risk factor at the same time (e.g., hypertension and diabetes mellitus). To account for the non-independence of the risk factors, the PAR AdjustedCombined formula (c) weights the PAR for each risk factor by using communality [2]. (a) $\mathrm{PAR}=($ prevalence of risk factor $\times(\mathrm{RR}-1)) /(1+$ prevalence of risk factor $\times(R R-1))$

(b) $\mathrm{PAR}_{\text {combined }}=1-\Pi 1-\mathrm{PAR}$, where $\Pi$ implies subtraction of one minus the risk factor, and then multiply each of the results

(c) $\mathrm{PAR}_{\text {AdjustedCombined }}=1-\Pi 1-(\mathrm{w} \times \mathrm{PAR})$, where the weight (w) was computed using the estimate of 1 minus the proportion of the variance shared with the other risk factors, which is the communality.

The communalities were obtained via principal components analysis of the inter-risk-factor tetrachoric correlation matrix of data derived from data of surveys containing measurements for each risk factor. In our analysis, we used the same communality scores from Norton et al. [2]. The total number of dementia cases was obtained through multiplying the total number of persons aged 65 years old or above (numbers available in http://www.worldometers.info) by the prevalence of dementia in each country: $3.5 \%$ in Mozambique, $7.0 \%$ in Brazil, and 9.2\% in Portugal $[1,20,21]$. The number of dementia cases attributable to each risk factor was then estimated by multiplying the PAR estimates by the present number of dementia cases in each country. To estimate the potential reduction of dementia cases in the future by reducing the prevalence of risk factors, we calculated a $10 \%$ or $20 \%$ reduction of the relative prevalence of each risk 
Table 2

Estimates for population-attributable risk and number of attributable cases

\begin{tabular}{|c|c|c|c|}
\hline Country & Prevalence & PAR $(95 \% \mathrm{CI})$ & $\begin{array}{l}\text { Number of attributable cases in } \\
2010(95 \% \text { CI }) \text { in thousands }\end{array}$ \\
\hline \multicolumn{4}{|l|}{ Mozambique } \\
\hline Diabetes mellitus & $2.9 \%$ & $1.3 \%(0.6-2.2)$ & $0.344(0.159-0.582)$ \\
\hline Midlife hypertension & $10.6 \%$ & $6.1 \%(1.7-11.6)$ & $1.614(0.450-3.070)$ \\
\hline Midlife obesity & $1.5 \%$ & $0.9 \%(0.5-1.4)$ & $0.238(0.132-0.371)$ \\
\hline Physical inactivity & $9.3 \%$ & $7.1 \%(1.7-14.2)$ & $1.879(0.450-3.758)$ \\
\hline Depression & $10.7 \%$ & $6.5 \%(4.3-9.0)$ & $1.720(1.138-2.382)$ \\
\hline Smoking & $21.4 \%$ & $11.2 \%(3.1-20.4)$ & $2.964(0.820-5.399)$ \\
\hline Low educational attainment & $44.9 \%$ & $20.9 \%(13.6-27.9)$ & $5.532(3.600-7.384)$ \\
\hline Combined & & $44.0 \%(23.4-61.8)$ & $11.645(6.193-16.357)$ \\
\hline Adjusted combined & & $24.4 \%(12.9-36.1)$ & $6.458(3.414-9.555)$ \\
\hline \multicolumn{4}{|l|}{ Brazil } \\
\hline Diabetes mellitus & $6.2 \%$ & $2.8 \%(1.2-4.6)$ & $25.976(11.133-42.675)$ \\
\hline Midlife hypertension & $7.4 \%$ & $4.3 \%(1.2-8.4)$ & $39.892(11.133-77.928)$ \\
\hline Midlife obesity & $7.5 \%$ & $4.3 \%(2.5-6.4)$ & $39.892(23.193-59.374)$ \\
\hline Physical inactivity & $46.0 \%$ & $27.4 \%(8.0-45.0)$ & $254.193(74.217-417.470)$ \\
\hline Depression & $7.6 \%$ & $4.7 \%(3.1-6.5)$ & $43.602(28.759-60.301)$ \\
\hline Smoking & $15.0 \%$ & $8.1 \%(2.2-15.3)$ & 75.145 (20.410-141.940) \\
\hline Low educational attainment & $45.1 \%$ & $21 \%(13.6-27.9)$ & $194.819(126.169-258.831)$ \\
\hline Combined & & $55.3 \%(28.3-74.3)$ & $513.024(262.542-689.289)$ \\
\hline Adjusted combined & & $32.3 \%(15.8-46.3)$ & $299.651(146.578-429.530)$ \\
\hline \multicolumn{4}{|l|}{ Portugal } \\
\hline Diabetes mellitus & $9.8 \%$ & $4.3 \%(1.9-7.0)$ & $7.844(3.466-12.770)$ \\
\hline Midlife hypertension & $19.8 \%$ & $10.8 \%(3.1-19.7)$ & $19.702(5.655-35.938)$ \\
\hline Midlife obesity & $15.7 \%$ & $8.6 \%(5.1-12.6)$ & $15.689(9.304-22.986)$ \\
\hline Physical inactivity & $53.9 \%$ & $30.7 \%(9.3-49.0)$ & $56.005(16.966-89.390)$ \\
\hline Depression & $16.7 \%$ & $9.8 \%(6.6-13.3)$ & $17.878(12.040-24.263)$ \\
\hline Smoking & $20.0 \%$ & $10.6 \%(2.9-19.4)$ & $19.337(5.290-35.391)$ \\
\hline Low educational attainment & $46.4 \%$ & $21.5 \%(14.0-28.5)$ & $39.222(25.540-51.992)$ \\
\hline Combined & & $65.8 \%(36.2-83.4)$ & $120.038(66.039-152.145)$ \\
\hline Adjusted combined & & $40.1 \%(20.7-55.4)$ & $73.154(37.763-101.065)$ \\
\hline
\end{tabular}

factor per decade and multiplied this by the number of dementia cases for that year. We used the same proportion of risk factor reduction and same timeline for projections as Norton et al., 2014 [2] to allow comparisons.

\section{RESULTS}

Figure 1 shows the prevalence of risk factors for dementia in each country and Table 2 the estimates of the PAR for dementia for each risk factor and the proportion of attributable cases in Portugal, Brazil, and Mozambique in 2010. As low educational attainment was similarly highly prevalent in the three countries, it was estimated that 2 in 10 cases of dementia were attributable to this risk factor. While physical inactivity was responsible for almost 3 in 10 cases of dementia in Portugal and Brazil, this was attributable to less than 1 in 10 cases in Mozambique. Midlife hypertension was more prevalent in Portugal (19.8\%) than in Brazil (7.4\%) and Mozambique (10.6\%), contributing to about 1 in 10 cases of dementia in Portugal, but less than 1 in 10 in Brazil and Portugal.

Midlife obesity accounted for $8.6 \%$ and $4.3 \%$ of cases of dementia in Portugal and Brazil, respectively, while this estimate was as low as $0.9 \%$ in Mozambique due to a much lower prevalence of this risk factor in that country. Smoking accounted for around $10 \%$ of the cases of dementia in the three countries, while depression accounted for almost $10 \%$ of cases in Portugal, but for only $4.7 \%$ of cases in Brazil and 6.5\% in Mozambique. Diabetes was among the least prevalent risk factor in all three countries, contributing to $1.3 \%, 2.8 \%$, and $4.3 \%$ of cases of dementia in Mozambique, Brazil, and Portugal, respectively. If we consider that each risk factor contributes to dementia prevalence independently, the seven risk factors accounted for $44.0 \%$ of dementia cases in Mozambique, 55.3\% in Brazil, and 65.8\% in Portugal. The communality scores for risk factor attribution in the three countries were high (from $37.4 \%$ to $65.0 \%$, Table 1 ) and so the non-independent attributable number of cases was much lower in all 


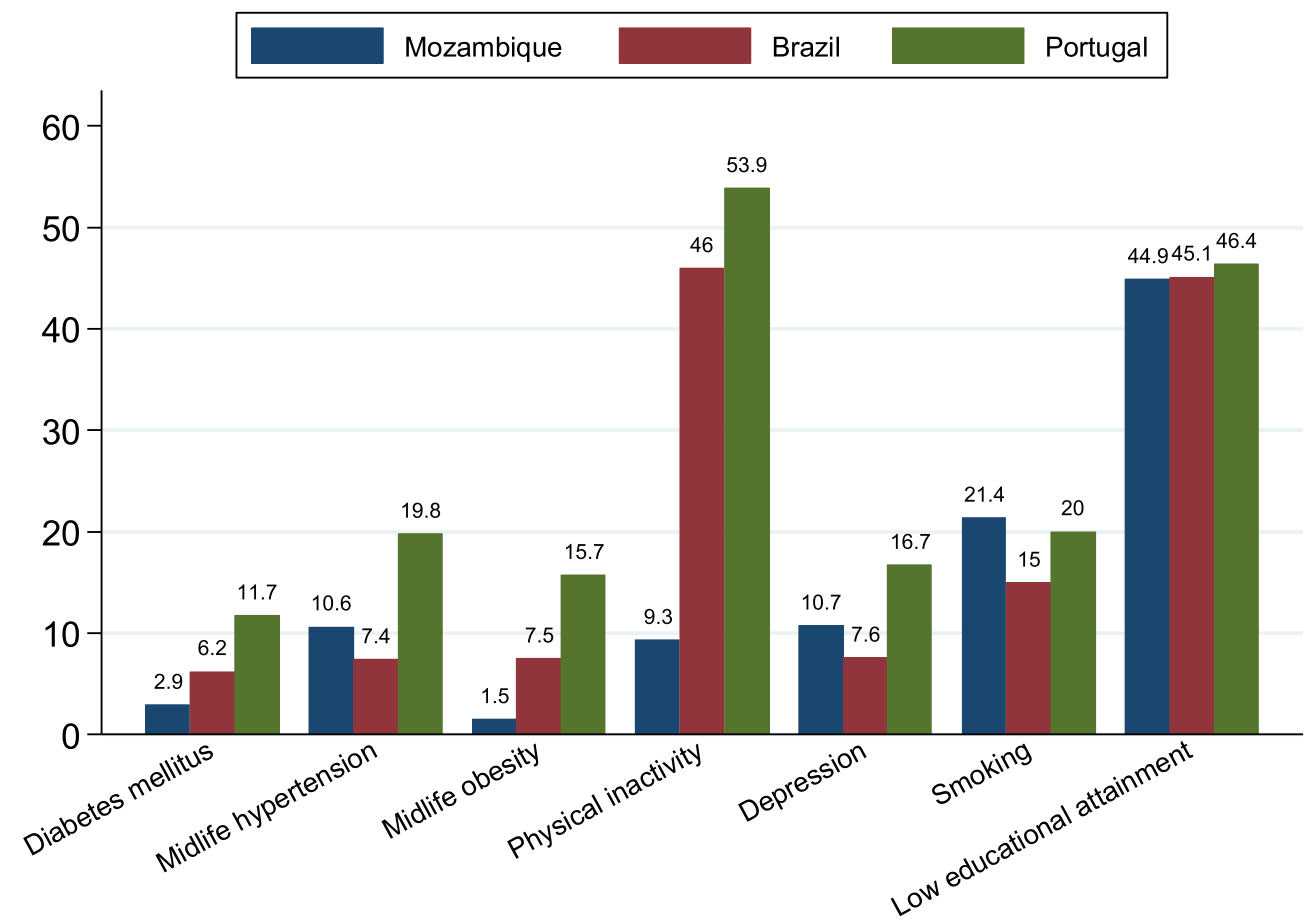

Fig. 1. Prevalence of risk factors for dementia in each country.

the three countries (24.4\% in Mozambique, $32.3 \%$ in Brazil, and $40.1 \%$ in Portugal).

Considering a reduction of $10 \%$ in the prevalence of these seven risk factors by 2020 , combined with the projections of population ageing in each country, there could be a reduction in the number of cases of dementia in Mozambique, Brazil, and Portugal of $1.9 \%, 2.3 \%$, and $2.7 \%$, respectively (Fig. 2 and Supplementary Table 1). By 2050, the prevalence of dementia could be reduced by $7.0 \%, 8.7 \%$, and $10.2 \%$ in the three countries. If the reduction in the prevalence of these risk factors was as high as $20 \%$, there would be a reduction of $12.9 \%$ of dementia in Mozambique, $18.1 \%$ in Brazil, and $20.9 \%$ in Portugal. Considering that the number of people with dementia is estimated to increase from 1.14 to 4.13 million by 2050 in these three countries combined, around 676 thousand cases could be prevented with a $20 \%$ reduction in the prevalence of these risk factors by 2050 .

\section{DISCUSSION}

This is the first study to investigate the potential for dementia incidence reduction in Mozambique, Brazil, and Portugal by estimating the population- attributable risk for seven potentially modifiable risk factors (low educational attainment, physical inactivity, midlife hypertension, midlife obesity, depression, smoking, and diabetes mellitus). After adjusting for the non-independence of risk factors, the findings suggest that $24.4 \%, 32.3 \%$, and $40.1 \%$ of dementia cases can be explained by seven potentially modifiable risk factors in Mozambique, Brazil, and Portugal, respectively. Reducing the prevalence of each risk factor by $10 \%$ or $20 \%$ per decade could potentially reduce the prevalence of dementia in 2050 by 7.0 or $12.9 \%$ in Portugal, 8.7 or $16.2 \%$ in Brazil, and 10.2 or $19.5 \%$ in Portugal. This has important implications for public health preventive actions, which could use this information to focus resources on the clinical and life style risk factors most responsible for potential increased numbers of people with dementia locally.

Given the equally high prevalence of low education attainment in Mozambique, Brazil, and Portugal (about $45 \%$ ), this risk factor accounted similarly for a large proportion of cases of dementia in all three countries (about 20\%). There was, however, a clear difference between them regarding the other risk factors and after adjusting for non-independence of risk factors $24.4 \%, 32.3 \%$, and $40.1 \%$ of dementia cases could be explained by seven potentially modifiable 


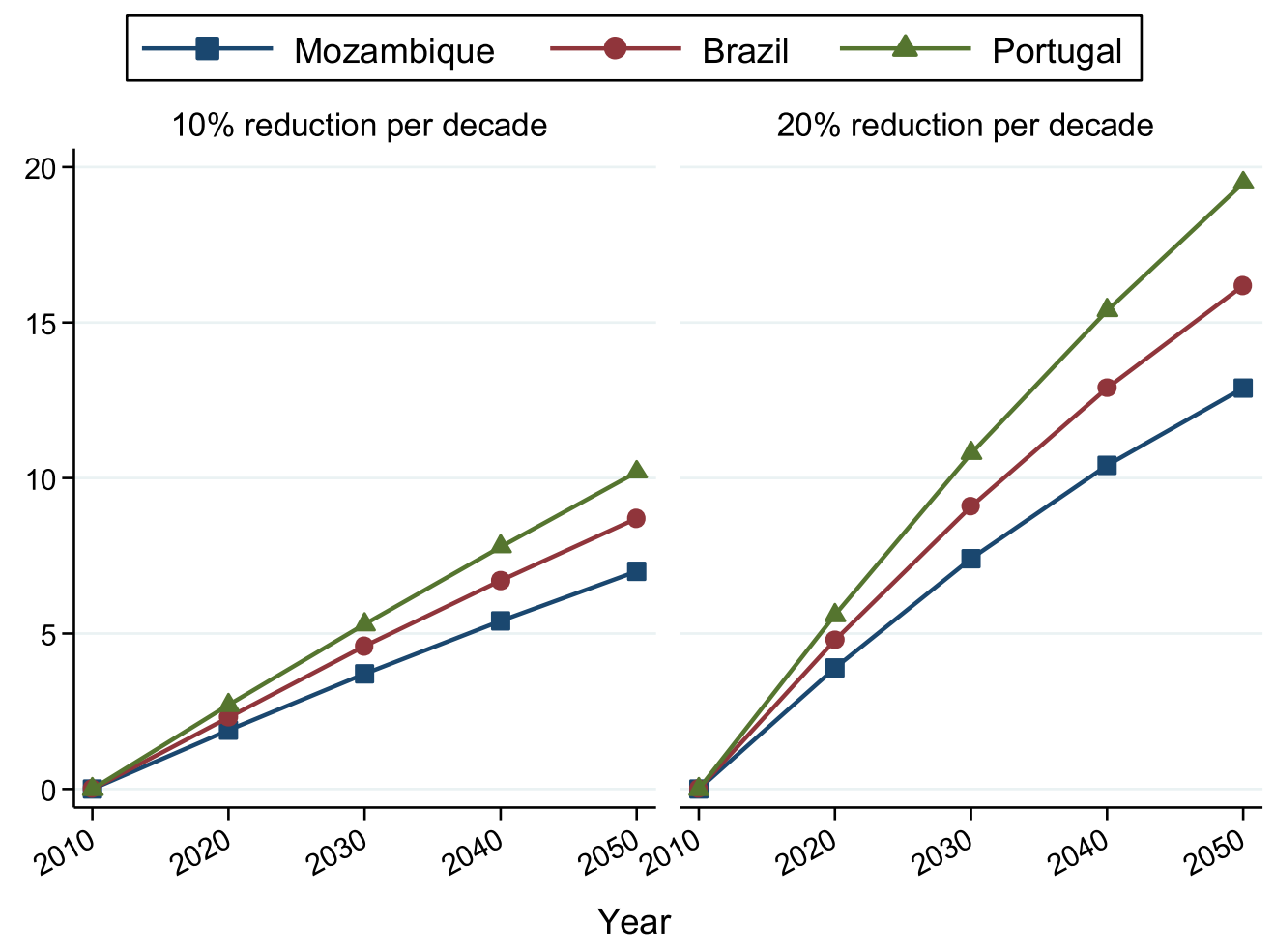

Fig. 2. Differences in estimated reduction of numbers of cases of dementia with $10 \%$ or $20 \%$ reduction per decade in the relative prevalence of the seven risk factors.

risk factors in Mozambique, Brazil, and Portugal respectively. The adjusted PAR we found for Portugal $(40.1 \%)$ appears to be overall higher when compared to two other high-income countries, using similar risk factors (UK: $30 \%$ and USA: 30.6\%) [2], but closer to what was found for Australia (48.4\%) [22] with a similar profile of risk factors contributing the most to current cases (physical inactivity and midlife hypertension). Low educational attainment was the only risk factor with similar prevalence and dementia population-attributable risk in the three countries, and it is a social determinant of many health-related behaviors and outcomes, including physical inactivity. Comparing previous studies using a similar methodology [2, 22], with the same seven risk factors considered, physical inactivity had the highest PAR in the USA (21\%), followed by the UK (20\%), and Australia (17.9\%). This was also the case in this study for Portugal $(\mathrm{PAR}=30.7 \%)$ and Brazil $(\mathrm{PAR}=27.4 \%)$ but not for Mozambique (PAR $=7.1$ ). Considering the gradual increases in income levels in Mozambique (low-income), Brazil (middle-income), and Portugal (high-income), it is interesting to note a parallel shift in the respective epidemiological profiles towards an increase in the prevalence of chronic conditions and physical inactivity. Overall, countries with lower incomes have less access to transport and technological resources, as well as industrialized food; these countries' populations may also have more agricultural activities or other jobs relying on physical effort; which might explain their lower prevalences of chronic diseases and higher levels of physical activity. On the other hand, such countries also have lower life expectancy and so we do not know for certain whether individuals would develop or would be exposed to some of the risk factors considered in this study and whether these would lead to dementia were their populations to live longer. Nonetheless, there is a 'window of opportunity' for lower-income countries to plan and implement actions that might interrupt this pattern by preventing people becoming less physically active, more obese, and of having hypertension and diabetes in the future. Increasing physical inactivity is likely to reduce obesity, hypertension, depression, and diabetes [23], contributing to large scale dementia risk reduction.

The strengths and limitations of the methods used to estimate the number of cases of dementia attributable to potentially modifiable risk factors in this study have been pointed out previously [2]. For 
example, the relative risk estimates are based on secondary data and the causes for several of the risk factors analyzed are unclear. There is also the fact that the prevalence of many of the dementia risk factors results from life-long experiences and the exact impact of improving each of these risk factors in different age groups is unclear. A longitudinal approach to these estimates accounting for several other interacting variables is needed. The prevalence estimates of the seven risk factors was taken from published studies, which have some limitations, including country representativeness. Dementia in LMICs is still under researched and underdiagnosed [24] so the prevalences used in the calculations might not represent the true number of people living with the condition in these areas, which might have affected the estimates provided. Although the adjusted combined estimates are robust, further research is needed to confirm these findings and the low-, middle-, and high -income countries comparisons could be expanded by gathering data from more countries. This study used the number of people living with all types of dementia in Portugal, Brazil, and Mozambique, so conclusions cannot be drawn about the impact of the seven investigated risk factors on each cause of dementia (e.g., vascular versus Alzheimer's disease). However, it has been argued that such risk factors are likely to contribute to more than one type of dementia and previous studies have shown that multi-domain approaches to dementia prevention are more likely to reduce the prevalence of the condition [25]. Such interventions may benefit cognition regardless of individual sociodemographic characteristics and vascular risk and can be implemented in large populations. This suggests that estimating the impact of risk factors on the prevalence of all types of dementia together might provide valuable predictions to inform public health actions aimed at reducing the number of people living with any type of dementia. This study did not consider other potential modifiable risk factors which may also contribute to dementia risk, such as diet, social isolation, sensory loss, air pollution, and sleep quality.

Our findings highlight the need for policy makers and public health services to understand and consider windows of opportunity to reduce different risk factors throughout lifespan globally and within diverse cultural and economic contexts. Most of the modifiable risk factors contributing to the highest rates of dementia in low-, middle-, and high-income countries are partly dependent on behavior change and policies are needed to strengthen public health actions. Global actions are needed to tackle the increasing prevalence of dementia worldwide and there is currently little research on the potentially modifiable risk factors for dementia in low- middle-income countries, where the number of people living with dementia are the highest.

The biological, environmental, social, and psychological interplay between the numerous risk factors and dementia onset is complex. The socioeconomic situation of many LMICs can be a limiting factor for dementia prevention as education and lifestyle are ultimately linked. Working towards dementia risk reduction is likely to help prevent several other chronic diseases and so there is a large potential for collaboration across and within health and social sectors which may optimize resources and effectiveness. Future research should focus on exploring the effects of such risk factors on dementia across lifespan and on the relationships among these different factors in respect of dementia onset in LMICs. Economic evaluations of dementia risk reduction in such countries are also likely to contribute to the development of affordable preventive practices for dementia [26].

\section{Conclusions}

The proportion of cases potentially preventable by acting upon the seven risk factors studied was greater in Portugal than in Brazil, and in Brazil was greater than in Mozambique. This finding might have been a reflection of the gradient found in the proportion of current cases attributable to the seven risk factors studied and of the substantial differences found in the prevalence of each risk factor in each country. Our findings partially reflect the demographic and epidemiological transition stage of the countries studied, with a gradual parallel increase in the prevalence of the chronic conditions and unhealthy behaviors associated with dementia. All three countries need to improve the education levels of their populations, and higher-income countries need an urgent approach to improving physical activity. Different countries and regions may need to pursue different strategies for dementia risk reduction based on their unique demographic and risk factor profiles.

Future research should focus on exploring the effects and impact of such risk factors on dementia across lifespan and on the relationships among these several factors in respect of dementia onset in LMICs. Also, larger study of groups from low-, middle-, and high-income countries, using good quality data from local well conducted studies on the national preva- 
lence of each risk factor are required to explore these relationships in more detail.

\section{ACKNOWLEDGMENTS}

JL is supported by the Fundação de Amparo à Pesquisa do Estado do Rio de Janeiro (FAPERJ) and by Conselho Nacional de Pesquisa (CNPq) and CF by the Conselho Nacional de Pesquisa (CNPq) and Associação Fundo de Incentivo a Pesquisa (AFIP).

Authors' disclosures available online (https:// www.j-alz.com/manuscript-disclosures/18-0636r1).

\section{SUPPLEMENTARY MATERIAL}

The supplementary material is available in the electronic version of this article: http://dx.doi.org/ 10.3233/JAD-180636.

\section{REFERENCES}

[1] Prince M, Wimo A, Guerchet M, Ali G-C, Wu Y-T, Prina M (2015) World Alzheimer Report 2015: The Global Impact of Dementia, https://www.alz.co.uk/research/world-report2015. Accessed on November 28, 2018.

[2] Norton S, Matthews FE, Barnes DE, Yaffe K, Brayne C (2014) Potential for primary prevention of Alzheimer's disease: An analysis of population-based data. Lancet Neurol 13, 788-794

[3] Livingston G, Sommerlad A, Orgeta V, Costafreda SG, Huntley J, Ames D, Ballard C, Banerjee S, Burns A, CohenMansfield J, Cooper C, Fox N, Gitlin LN, Howard R, Kales HC, Larson EB, Ritchie K, Rockwood K, Sampson EL, Samus Q, Schneider LS, Selbæk G, Teri L, Mukadam N (2017) Dementia prevention, intervention, and care. Lancet 390, 2673-2734.

[4] Frankish H, Horton R (2017) Prevention and management of dementia: A priority for public health. Lancet 390, 26142615.

[5] Brasil (2018) Instituto Brasileiro de Geografia e EstatísticaIBGE, https://ww2.ibge.gov.br/english/, Accessed on May $1,2018$.

[6] Silva-Matos C, Gomes A, Azevedo A, Damasceno A, Prista A, Lunet N (2011) Diabetes in Mozambique: Prevalence, management and healthcare challenges. Diabetes Metab 37, 237-244.

[7] Barreto M, Gaio V, Kislaya I, Antunes L, Rodrigues AP, Silva AC, Vargas P, Prokopenko T, Santos AJ, Namorado S, Gil AP, Alves Alves C, Castilho E, Cordeiro E, Dinis A, Nunes B, Matias Dias C (2015) $1^{\circ}$ Inquérito Nacional de Saúde com Exame Físico (INSEF 2015): Estado de Saúde, http://www2.insa.pt/sites/INSA/Portugues/ComInf/ Noticias/Paginas/1INSEFrelat\%C3\%B3rio.aspx. Accessed on November 28, 2018.

[8] Barnes DE, Yaffe K (2011) The projected effect of risk factor reduction on Alzheimer's disease prevalence. Lancet Neurol 10, 819-828.

[9] Damasceno A, Azevedo A, Silva-Matos C, Prista A, Diogo D, Lunet N (2009) Hypertension prevalence, aware- ness, treatment, and control in Mozambique: Urban/rural gap during epidemiological transition. Hypertension 54, 77-83.

[10] Gomes A, Damasceno A, Azevedo A, Prista A, SilvaMatos C, Saranga S, Lunet N (2010) Body mass index and waist circumference in Mozambique: Urban/rural gap during epidemiological transition. Obes Rev 11, 627-634.

[11] Padrão P, Damasceno A, Silva-Matos C, Prista A, Lunet N (2012) Physical activity patterns in Mozambique: Urban/rural differences during epidemiological transition. Prev Med 55, 444-449.

[12] Audet CM, Wainberg ML, Oquendo MA, Yu Q, Blevins Peratikos M, Duarte CS, Martinho S, Green AF, GonzálezCalvo L, Moon TD (2018) Depression among female heads-of-household in rural Mozambique: A crosssectional population-based survey. I Affect Disord 227, 48-55.

[13] Padrão P, Damasceno A, Silva-Matos C, Carreira H, Lunet N (2013) Tobacco consumption in Mozambique: Use of distinct types of tobacco across urban and rural settings. Nicotine Tob Res 15, 199-205.

[14] Chipembe CS, Guiliche F, Zacarias F, Maunze X, Cubula B, Zunguze C, Samo E, Mangue J, Alfeu M, Come R (2015) Relatório final do inquérito ao orçamento familiar - IOF2014/15, Instituto Nacional de Estatistica, Mozambique, http://www.ine.gov.mz/operacoes-estatisticas/inqueritos/in querito-sobre-orcamento-familiar/relatorio-final-do-inquer ito-ao-orcamento-familiar-iof-2014-15/view. Accessed on November 28, 2018.

[15] World Health Organization (2013) Portugal - WHO Country Profile. Nutrition, Physical Activity and Obesity, http:// www.euro.who.int/en/countries/portugal/publications/coun try-profiles-on-nutrition,-physical-activity-and-obesity-inthe-53-who-european-region-member-states.-methodology -and-summary-2013 Accessed on November 28, 2018.

[16] Carreira H, Pereira M, Azevedo A, Lunet N (2012) Trends in the prevalence of smoking in Portugal: A systematic review. BMC Public Health 12, 958.

[17] European Commission. Educational attainment statistics - Statistics Explained, https://ec.europa.eu/eurostat/ statistics-explained/index.php/Educational_attainment_ statistics. Accessed on November 28, 2018.

[18] OECD (2014), Education at a Glance 2014: OECD Indicators, OECD publishing. Portugal - Country Note. http://dx.doi.org/10.1787/eag-2014-en

[19] Levin ML (1953) The occurrence of lung cancer in man. Acta Unio Int Contra Cancrum 9, 531-541.

[20] Fagundes SD, Silva MT, Thees MFRS, Pereira MG (2011) Prevalence of dementia among elderly Brazilians: A systematic review. Sao Paulo Med J 129, 46-50.

[21] Gonçalves-Pereira M, Cardoso A, Verdelho A, Alves da Silva J, Caldas de Almeida M, Fernandes A, Raminhos C, Ferri CP, Prina AM, Prince M, Xavier M (2017) The prevalence of dementia in a Portuguese community sample: A 10/66 Dementia Research Group study. BMC Geriatr 17, 261.

[22] Ashby-Mitchell K, Burns R, Shaw J, Anstey KJ (2017) Proportion of dementia in Australia explained by common modifiable risk factors. Alzheimers Res Ther 9, 11.

[23] World Health Organization (2009) Global health risks: Mortality and burden of disease attributable to selected major risks, Geneva, Switzerland, https://www.who.int/ healthinfo/global_burden_disease/GlobalHealthRisks_repo rt_full.pdf. Accessed on November 28, 2018. 
[24] Nakamura AE, Opaleye D, Tani G, Ferri CP (2015) Dementia underdiagnosis in Brazil. Lancet 385, 418-419.

[25] Rosenberg A, Ngandu T, Rusanen M, Antikainen R, Bäckman L, Havulinna S, Hänninen T, Laatikainen T, Lehtisalo J, Levälahti E, Lindström J, Paajanen T, Peltonen M, Soininen H, Stigsdotter-Neely A, Strandberg T, Tuomilehto J, Solomon A, Kivipelto M (2018) Multidomain lifestyle intervention benefits a large elderly population at risk for cognitive decline and dementia regardless of baseline characteristics: The FINGER trial. Alzheimers Dement 14, 263-270.

[26] Ferretti C, Sarti FM, Nitrini R, Ferreira FF, Brucki SMD (2018) An assessment of direct and indirect costs of dementia in Brazil. PloS One 13, e0193209. 